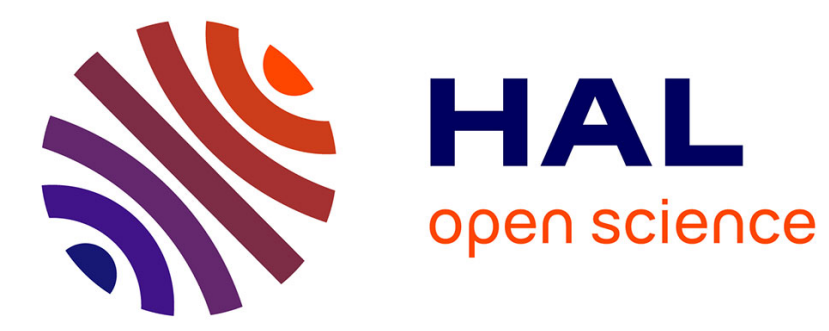

\title{
Design Entity Recognition for Bio-inspired Design Supervised State of the Art
}

\author{
Davide Russo, Pierre-Emmanuel Fayemi, Matteo Spreafico, Giacomo Bersano
}

\section{To cite this version:}

Davide Russo, Pierre-Emmanuel Fayemi, Matteo Spreafico, Giacomo Bersano. Design Entity Recognition for Bio-inspired Design Supervised State of the Art. 18th TRIZ Future Conference (TFC), Oct 2018, Strasbourg, France. pp.3-13, 10.1007/978-3-030-02456-7_1 . hal-02279772

\section{HAL Id: hal-02279772}

\section{https://hal.inria.fr/hal-02279772}

Submitted on 5 Sep 2019

HAL is a multi-disciplinary open access archive for the deposit and dissemination of scientific research documents, whether they are published or not. The documents may come from teaching and research institutions in France or abroad, or from public or private research centers.
L'archive ouverte pluridisciplinaire HAL, est destinée au dépôt et à la diffusion de documents scientifiques de niveau recherche, publiés ou non, émanant des établissements d'enseignement et de recherche français ou étrangers, des laboratoires publics ou privés. 


\title{
Design entity recognition for Bio-inspired Design supervised state of the art
}

\author{
Davide Russo $^{1}$, Pierre-Emmanuel Fayemi ${ }^{2}$, Matteo Spreafico ${ }^{1,}$ Giacomo Bersano ${ }^{2}$ \\ ${ }^{1}$ Bergamo University, 24044 Dalmine (BG), Italy \\ ${ }^{2}$ IKOS Consulting, Levallois-Perret, France
}

\begin{abstract}
In the last years the efforts spent for the enhancement of parsing engines led to several software more performant, in terms of both effectiveness in identification of syntax modules and speed of elaboration of the text, than the previous generation ones. Exploiting the benefits coming from such a new generation of software, nowadays the patent search can overcome the limits due to the classic FOS approach and performs it in a quasi-real-time way. This paper focuses on technical-problems identification methods based on syntactic dependency patterns, for ameliorating supervised state of the art and patent intelligence. Through parsing the patent text, very precise lists of technical problems are automatically extracted without the user being an expert in the problems of the sector. An exemplary case dealing with bio-inspired design is proposed, stressing what types of engineering problems are nowadays benefitting the most from the approach.
\end{abstract}

Keywords: Biomimetics, Biomimicry software, Triz, Syntactic parser

\section{Introduction}

Over the last years there has been an increment of papers regarding both TRIZ and biomimicry. The greatest efforts were produced to introduce TRIZ fundamentals, like technical contradictions or function modeling as tools for knowledge transfer of biological organisms, in order to solve technical problems.

A vast literature has been produced about this topic, even if spread under different labels (biomimetics, bionics, bio mimesis, biomimicry, bio gnosis, biologically inspired design).

The main part of these works is focused on new methods for searching biological literature for functional analogies to implement, while only few papers such as [1] suggest how to make successful the transfer of a concept from living to non-living systems. As Vincent said in [2] "a simple and direct replica of the biological prototype is rarely successful, even if it is possible with current technology".

There are many reasons for explaining these difficulties that we summarized in two main aspects: interdisciplinarity and function modelling.

In the first case there is a communication problem, in fact the most acknowledged database of biomimetics knowledge are run by biologists, which not necessarily describe a living organism for technicians looking for functions and the most 
appropriate biological resources suitable for addressing an engineering problem. However, it is not only a language problem, that could be partially solved by Bridging cross-domain terminology for biomimetic design [3], but what is intimately different is the way a biologist and an engineer look at the solution. For example, while an engineer describes a material in terms of performance or technical specifications and manufacturing requirements, biologist take into account how in natural systems a long-term evolution allows a homogeneous material to change locally and temporally its structure variables, expanding the design space of homogeneous materials and allowing the creation of new materials with specific property profiles [4]. From the nature perspective, instead of developing new materials each time we want new functionality, we should adapt and combine the materials we already have. Bogatyrev in $[2,5]$ contributed to prove this thesis demonstrating how technology solves problems largely by manipulating usage of energy, while biology uses information and structure, two factors largely ignored by technology.

The second bottleneck consists of creating efficient functional models for describing the complexity of natural system. Several attempts have been produced starting from implementing models from conceptual design as Energy Material Signal model [21], cause effect [6], functional basis [7] or Function Behavior Structure model [8]. Also, TRIZ community provided a significant contribution on this topic.

TRIZ was developed as a systems approach for engineering; biology is, itself, a system. Starting from this assumption, the conflicting functions are similarly classified into the standard TRIZ [9] features, which now allow the conflicts to be treated in the standard TRIZ system. Many authors [2,5,10,11] provided several works about conflicts identification in biomimicry, trying to interpret natural phenomena as technical contradiction and identifying resources and inventive principles adopted for overcoming the technical conflicts.

The article presents a synthesis of the major features characterizing a natural system in order to fix what entities has to be highlighted during biology transfer in section 2. In section 3, it illustrated the methodological proposal to retrieve the state of the art and the way of proceeding conducted in this study. After, in section 4, an example of the methodology through a case study is provided. Section 5 presents the results achieved from the case study. In closing, section 6 , the conclusion.

\section{Software for biomimetics}

While several computerized solutions have emerged over the years [13], two of them, i.e. AskNature and DANE, seems to prevail among the bioinspired design software.

\subsection{Asknature}

AskNature is a well establish tools within the bio-inspired design toolset. Known for being the largest database related to bio-inspiration, the tool aims at initiating pathways between natural phenomena, living organisms presenting such phenomenon and potential experts of the considered organisms [14]. 
To enable this, the database behind the AskNature website articulates itself around a specific ontology, called Biomimicry Taxonomy, based on a classification of functional keywords. This classification scheme is organized according to three hierarchical levels: eight categories (e.g. get, store, or distribute resources), thirteen sub-groups (e.g. capture, absorb, or filter, expel) and 162 functions (e.g. organisms, solid particles, chemical entities) [15]. By focusing on organizing biology by challenge, the taxonomy enables designers to translate their technical problematic, usually formalized with their specific professional jargon, to biological ones [16].

Through this mechanism of classification, the Biomimicry Taxonomy has been thought to be a key entry point of AksNature which encompasses descriptions of the biological strategies organisms use to tackle the problems they encounter [14].

AskNature has been at the forefront of the bio-inspired design tools for approximately a decade, and as such is part of the $48 \%$ of BID tools available as open source [13]. Its free access to its content

As one of the first biomimetics tools with a free and publicly access to its content as a constitutive element [14]. AskNature is one of the tool to have initiated the remaining trend toward open-source among the BID tools [13]. The combination of AskNature and its Biomimicry Taxonomy has been identified as one of the simplest and quickest way to implement biomimicry [17]. This accessibility seems to have made a difference regarding its use, with AskNature website being the only tool mentioned in interviews with biomimetic products developers [18].

Being for approximately a decade at the forefront of the bio-inspired design tools, AskNature has acted over the years as a catalyst in the expansion of the biomimetic toolset (e.g. BIOPS, a tool guiding the user to the websites asknature.org, to a patent database (freepatentsonline.com) and/or to scientific literature (sciencedaily.com) in order to find more information.; the Scalable Systematic Biologically-Inspired Design approach [19].

\subsection{DANE}

Functional modelling has been a major way of describing investigated systems for the bioinspired design process [20]. In 2007, Tinsley et al. have introduced a new way to convert biological knowledge, and especially design solutions, into valuable input for problem solving. This conversion, based upon functional language modeling has been pushed forward in the early 2010's by [21] who proposed general guidelines to formalize a biological system according to a functional representation integrating criterion such as its inspirational type and its scale.

Biological functional models offer the possibility to easily compile them into databases. Designer would thus be able to look for and identify analogous biological model relevant to their initial problematic. [22] have defined a problem-driven biologically inspired design process which provides iterative feedback and refinement loops. The process founds its foundations within the analysis of how students from the interdisciplinary course on biologically inspired design at Georgia Institute of Technology (ME/ISyE/MSE/PTFe/BIOL 4803) were implementing their BID approach throughout the progress of their case study. 
Projects analysis lead to a synthetic 6-steps process, as shown in the following figure:
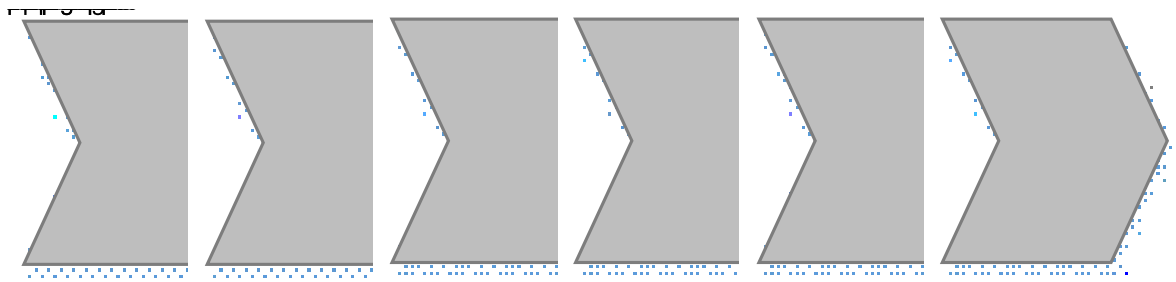

Fig. 1: Problem-Driven Biologically Inspired Design Process [22].

In order to make this analogical reasoning accessible for the designers who do not possess any biological background, [8] have developed both a computer aided design knowledge-based software and a representation scheme called DANE (Design by Analogy to Nature Engine). This approach focuses on generating a custom-built database, which is, de facto, dependent on the addition of new engineering and biologically representations.

The specificity of DANE generated models is their main focuses on describing in a detailed way the internal structure and functions of a system. Within the representation scheme, functions are modeled through a progression of states, linked together by behavioral causal explanations, along with structure box diagrams, highlighting the physical parameters involved in each of them.

DANE representation mainly focuses on two distinct designers' need: find a biological analogy relevant to a given design context and facilitate the understanding of biological systems so that anyone can extract then transfer the key functional principles.

In this model, the function is represented by means of a schema that specifies "initial" and "final" conditions of the system, with the aim of representing what the system actually does.

The function (defining the "why" of a system) is accomplished through a progression of states through which the system evolves, each described by a set of physical variables defining the relevant properties of the system.

The behavior (defining the "how" of a system) consists of this sequence of states, together with the causal explanation of the transition between them (Design \& Intelligence Laboratory - Georgia Tech, 2011). Usually, these explanations consist in a physical phenomenon or principle that governs the state transition.

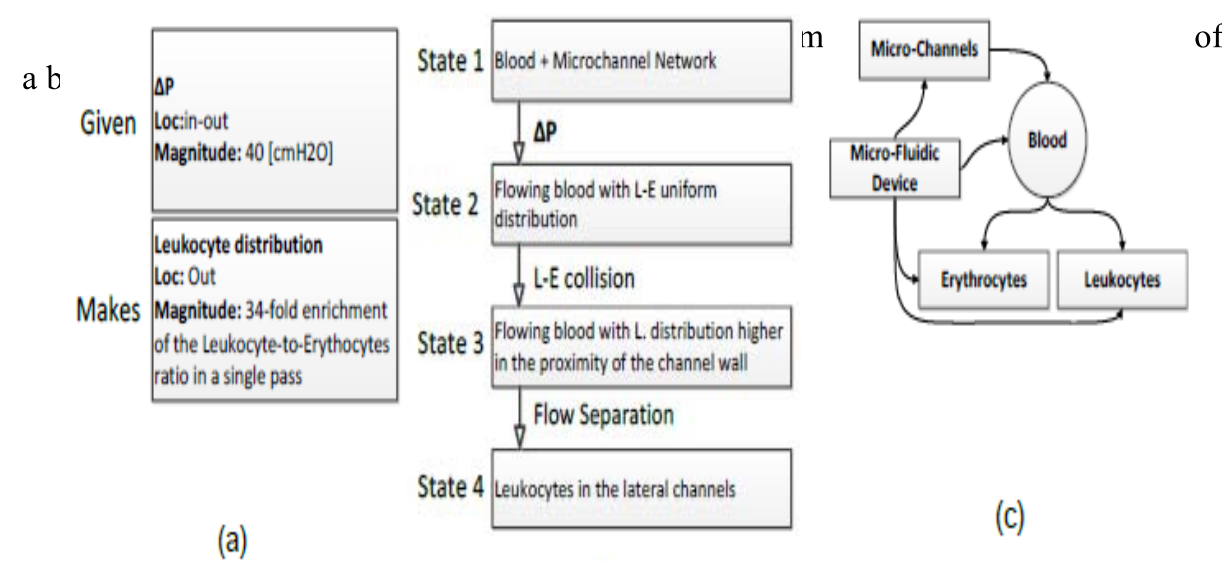


The compiled representation defines the computer aided design software called DANE 2.0. The tool focuses on establishing structured descriptions of biological systems and offering creative triggers by allowing designers to tap into a database of DANE representations of both engineering and biological examples.

\section{Proposal}

As a means to test the method proposed in this work, the authors have considered the extraction in full text (i.e. title, abstract, description, claims and priority dates) regarding the whole patent set and all scientific publications (from scientific journals, books and conference proceedings) concerning the field of biomimicry. They are interested on a wide investigation about this branch, so no specific topics was defined to limit the number of documents analyzed. 


\section{Extraction of the scientific paper and the patent corpus}

The authors used Orbit Intelligence (www.orbit.com) to querying the worldwide patent DB and Scopus (www.scopus.com) in order to interrogate scientific literature.

The goal is to extract the largest set of documents with the aim to study the problem in a complete and exhaustive way. It follows a schematic representation of the search queries with the results obtained.

The patent corpus considered for this study is a collection of 20770 patents belonging to different application fields and 46612 scientific publications owning searched with the following query: "(biomimicry) or (biomimetic + ) or (bio inspir + )".

Below is a flowchart that describes, schematically, the way of proceeding conducted in this study:

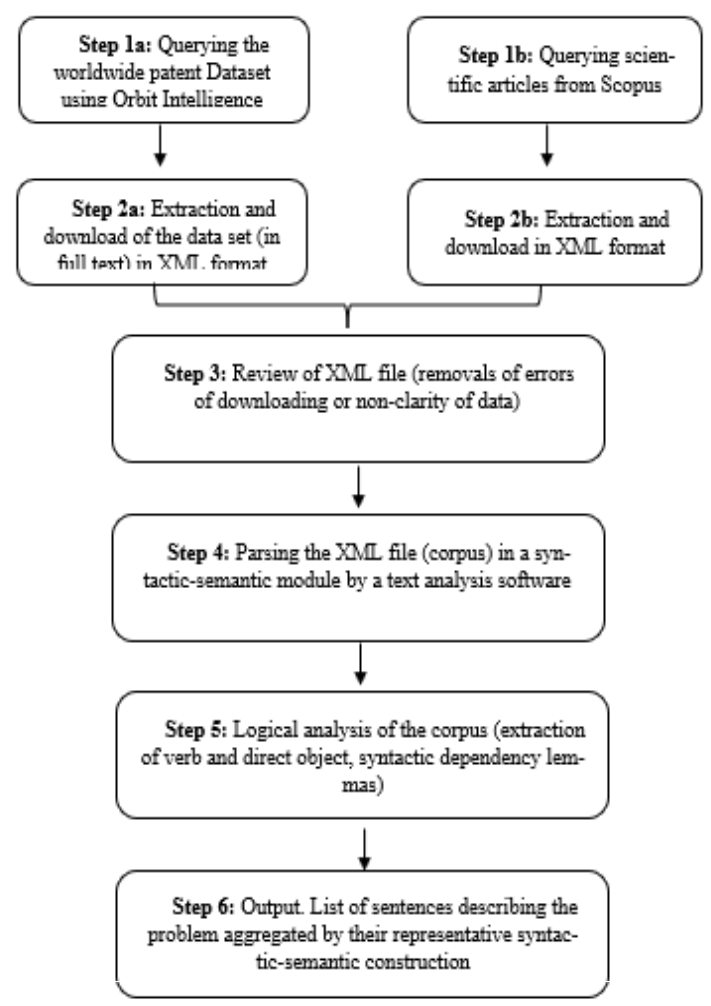

documents.

\section{Description of the flowchart above:}

The above method consists of the following steps:

- Step 1 a and b: Querying the worldwide dataset concerning patents and scientific articles. To test this new methodology, we did a search for all those that are articles and patents that speak of biomimicry. We started with this approach on a wide investigation about this branch, so no specific topics was defined to limit the number of documents analyzed. The ultimate goal is to work with a dataset containing only biological

- Step 2a and b: The extraction of the files took place using the xml format, a structural document with pre-defined tags, XML is a document that acts as a container to store data that can be used by other software and easy to open.

- Step 3 and 4: Revision of the file from a semantic point of view in order to prepare the file to be searched according to complex and linguistically motivated 
queries. The procedure starts analysing the raw text through a set of algorithmic operations that enrich the above-mentioned text with additional features.

With more detail, the procedure is as follows:

Conversion of the corpus text into a series of single words (tokens).

Generation of a tag by the text analysis software that represents the part-ofspeech (PoS) of that token.

1 In this way, the model becomes able to discriminate similar words with different meanings from a logical and syntactic point of view.

- Step 5: Extrapolation, from the corpus, of syntactic lemmas in order to provide a sample to be read list of functions. In order to extract only the useful information from the entire corpus set, the method gives to the searcher the list of sentences aggregated by their representative syntactic-semantic construction.

- Step 6: The proposal aims to give a sample to be read list of functions and technical problems through the parsing of the patent and scientific articles dataset. The tool gives, as a final output, a list of sentences describing the problem aggregated by their representative syntactic-semantic construction.

\section{Case Study}

In the following, a comparative analysis between ASKNATURE and semantic tools is presented. The selected input function has been the conductivity of electrical impulses. The topic selection has been made arbitrarily on the basis of the importance of electrical impulse in both living and technical systems.

\subsection{AskNature}

The biomimicry taxonomy possessed a specific entry related to electrical conductivity:

- Group: Modify

- Subgroup: Modify chemical/electrical state

- Function: Modify conductivity

This "modify conductivity" has been used has the input to tap into the AskNature datbase. AskNature offered two "solutions" in the form of two distinct strategies.

The first one is the inner-ear cells from vertebrates which convert sound signal to electrical current. The second one is the microbial nanowires of geobacter which transfer electrons in order to "breathe" mineral instead of oxygen.

A second function, belonging to the same "Modify chemical/electrical state" sub group, could have been relevant considering the initial query: "Modify electron transport". However, result of this specific function within the database exclusively shows the geobacter solution which was already identified.

\subsection{Scientific paper and the patent corpus}


The patent corpus \& scientific publications set was trimmed down from the previous set, i.e. ((biomimicry) or (biomimetic + ) or (bio_inspir+)), with the following results:

Table 1. List of queries and related results

\begin{tabular}{|c|c|c|}
\hline & Search queries & $\#$ of results \\
\hline Patent corpus & $\begin{array}{l}\text { ((biomimicry) or } \\
\text { (biomimetic }+ \text { ) or } \\
\text { (bio_inspir+))/TI/AB/IW/TX }\end{array}$ & 20770 \\
\hline Scientific publication set & $\begin{array}{l}\text { ((biomimicry) or } \\
\text { (biomimetic+) or } \\
\text { (bio inspir }+ \text { )) }\end{array}$ & 46612 \\
\hline
\end{tabular}

According to author's strategies, all sematic network among words has been extracted. In order to retrieve interesting documents acting on "electrical conductivity" applications, a list of verbs having "electrical conductivity" as object has been produced as shown in table 2 .

The documents analyzed are those containing propositions having actions dealing with improvement task (i.e. improve, increase, enhance, provide, upgrade, etc.) as object.

Table 2. List of lemmas related to "electrical conductivity" as objects

\begin{tabular}{|c|c|c|}
\hline & occurrence & rank \\
\hline verbs with "electrical conductivity" as object & 230 & 36.86 \\
\hline have & 72 & 8.49 \\
\hline improve & 25 & 6.84 \\
\hline$\ldots \ldots \ldots \ldots \ldots \ldots \ldots \ldots$ & $\ldots \ldots$ & $\ldots \ldots \ldots$ \\
\hline include & 10 & 6.4 \\
\hline measure & 8 & 5.93 \\
\hline maintain & 8 & 5.6 \\
\hline increase & 8 & 5.31 \\
\hline enhance & 7 & 5.03 \\
\hline provide & 6 & 4.59 \\
\hline exhibit & 6 & 4.38 \\
\hline 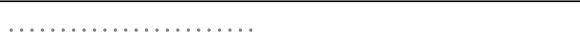 & ...... & $\ldots \ldots \ldots$ \\
\hline achieve & 3 & 3.37 \\
\hline impart & 2 & 3.34 \\
\hline decrease & 2 & 3.03 \\
\hline 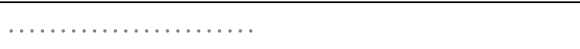 & $\ldots \ldots$ & $\ldots \ldots \ldots$ \\
\hline reduce & 1 & 1.99 \\
\hline
\end{tabular}




\begin{tabular}{|l|r|l|}
\hline \hline promote & 1 & 1.76 \\
\hline lower & 1 & 1.7 \\
\hline involve & 1 & 1.64 \\
\hline incorporate & 1 & 1.57 \\
\hline evaluate & 1 & 1.52 \\
\hline enable & 1 & 1.38 \\
\hline$\ldots \ldots \ldots \ldots \ldots$ & $\ldots \ldots$ & $\ldots \ldots \ldots$ \\
\hline
\end{tabular}

\section{$5 \quad$ Results}

Results from the case study, summarized in table 3 stressed differences between the use of AskNature and the semantic research tool which could be classified according to two categories: quantity and quality.

With a quantity focus, AskNature has shown its limitation in enlarging designer's scope of knowledge with only two highlighted possible solution, labelled "sensor" and "nanowires". This identified weakness seems to be induced by the design of the tool. In order to be populated, AskNature requires biologists to formalize content from their expertise. The process of mobilizing these biologists proves to be tedious as well as time consuming. This limits the tool's exhaustiveness compared to tools capable of automatically screening scientific literature. From its largest scope of investigation, the semantic tool has been able to identify seven possible solutions, labelled "Nanofiber", "Doped carbon", "Microelectrodes", "Electro spraying", "Aerogel", "Carbon nanotubes" and "polymer actuators".

On the quality aspect, the semantic tool's approach tends to offer better results. Compared to AskNature, the semantic approach offered a largest variety of solutions typology. While AskNature specifically promoted "technological solutions", the semantic tool highlighted almost $60 \%$ (4 results) of "technological solution" for around $40 \%$ ( 3 results) of "strategic principles". In addition to this, both volume and precision of the available information were higher through the semantic approach. Information gathered through ask nature consisted of an average 436 words resulting from a popularization of scientific content, which significantly less than any patent or scientific article both in number of words or comprehensiveness.

Table 3. Summary of "conductivity of electrical impulses" from both AskNature, scientific papers and patent corpus 


\begin{tabular}{|c|c|c|c|c|c|c|c|}
\hline & $\mid$ & 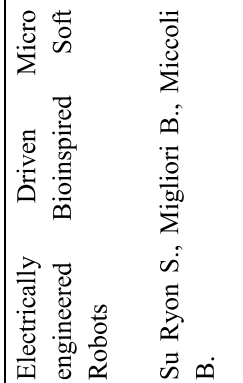 & 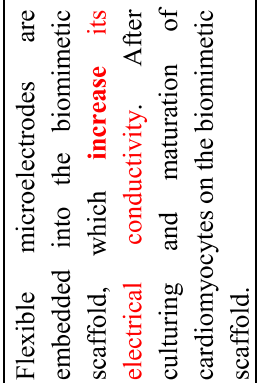 & & & 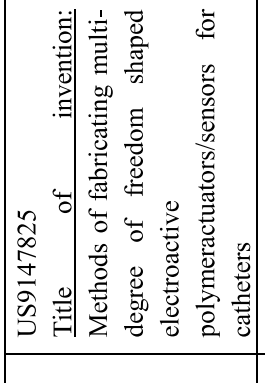 & 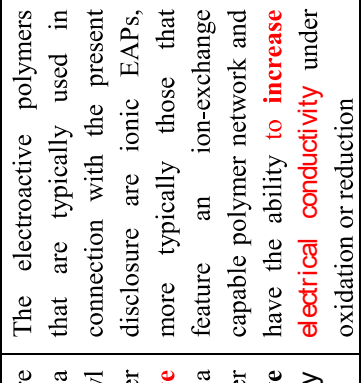 \\
\hline & & 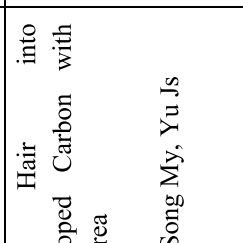 & 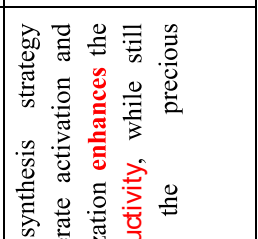 & & 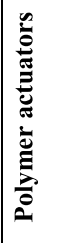 & 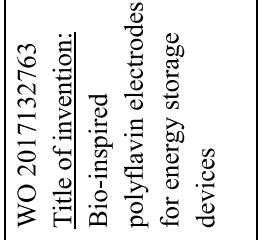 & 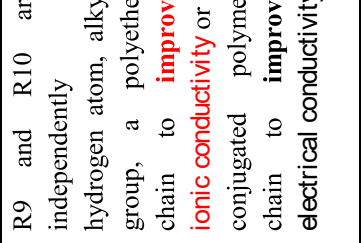 \\
\hline & & 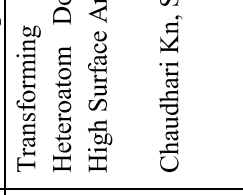 & 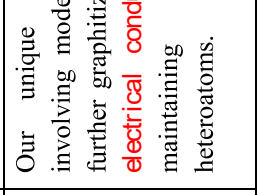 & & & 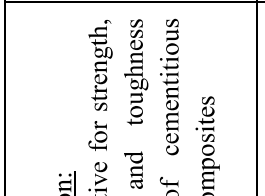 & 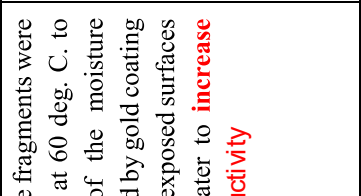 \\
\hline & & 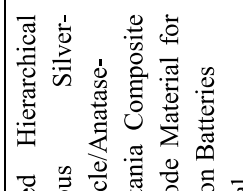 & 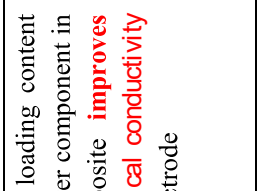 & ؛ & & 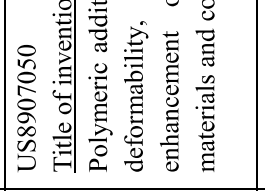 & 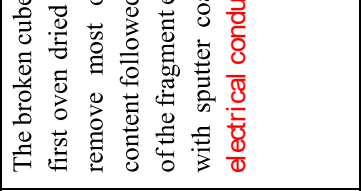 \\
\hline & & 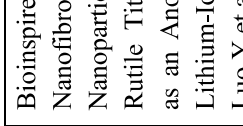 & 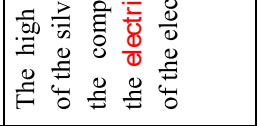 & & 递 & & 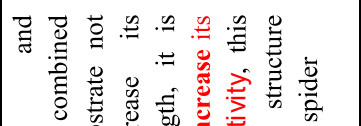 \\
\hline & 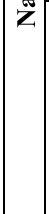 & 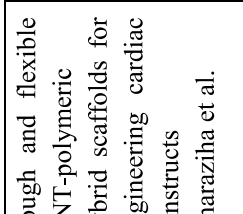 & 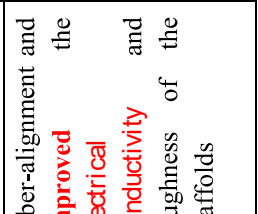 & & 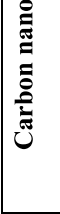 & 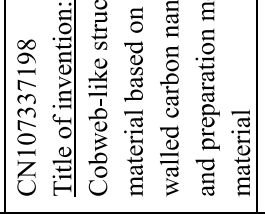 & 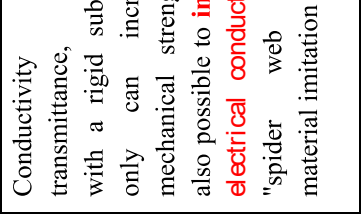 \\
\hline & & & & & & & $\underline{\mathrm{g}}$ \\
\hline & & & 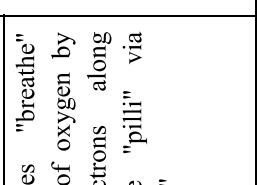 & & 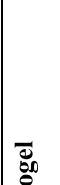 & 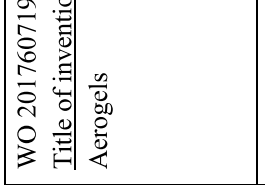 & 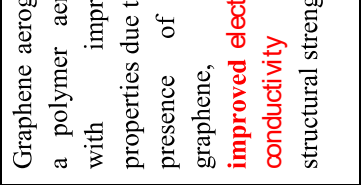 \\
\hline & & & 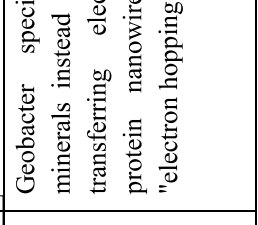 & & 4 & 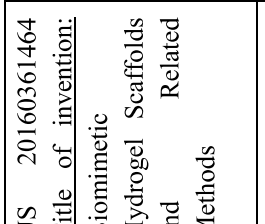 & 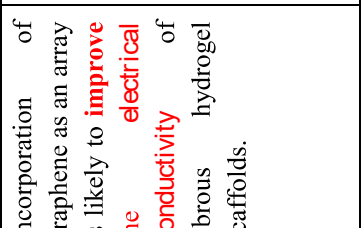 \\
\hline & & 6 & 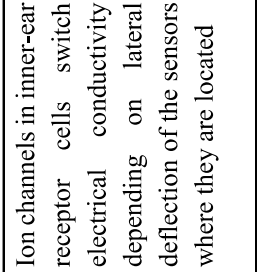 & & 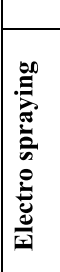 & 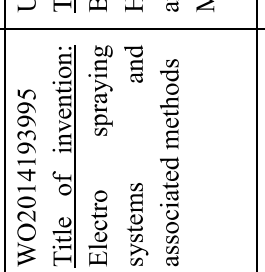 & 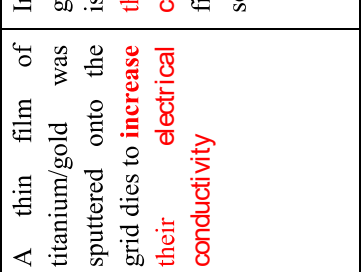 \\
\hline
\end{tabular}




\section{Conclusion}

Test on a database that already has examples of bio-inspiration "written by engineers".

The limit of this case study relates to understand what is the organism that serves as inspiration. One must read the title of the article or the patent because, so far, it is necessary to read the title of the article or the patent because one does not have the preposition with which electrical conductivity and the organization relate directly.

If a scholar reads an article in biology, we can identify that we speak of improvement of electrical conductivity in an article about a fish. The relationship is much easier to find. But to begin with, it was easier to skew the experience because it ensured a certain number of results with more writing by engineers and not biologists, reducing the semantic bias.

Future development does not use the database on biomimetics but uses the articles of biology. In the future we can use directly in biological databases to find strategies to solve problems 


\section{References}

1. Sartori, J., Ujjwal Pal, and Chakrabarti A. A methodology for supporting transfer in biomimetic design, Artificial Intelligence for Engineering Design, Analysis and Manufacturing (Cambridge University Press), 2010, 483-505.

2. Vincent, J. F.V., et al. Biomimetics: its practice and theory, Journal of the Royal Society Interface 3.9, 2006, 471-482.

3. Chiu I., and L. H. Shu. Bridging cross-domain terminology. ASME 2005 International Design Engineering Technical Conferences and Computers and Information in Engineering, 2005.

4. Wegst U.G.K, Ashby M.F The mechanical efficiency of natural materials. Phil. Mag 84, 2004, 2167-2186.

5. Bogatyrev N.R. In Ecological engineering of survival, Novosibirsk, Russia: Publishing house of SB RAS, 2000

6. Chakrabarti, A., et al. A functional representation for aiding biomimetic and artificial inspiration of new ideas. AIE EDAM 19.02 (2005): 113-132.

7. Stroble, Jacquelyn K., et al. Modeling the cellular level of natural sensing with the functional basis for the design of biomimetic sensor technology. Region 5 Conference, 2008 IEEE. IEEE, 2008.

8. Vattam S., Wiltgen B., Helms M., Goel A. and Yen J. DANE: fostering creativity in and through biologically inspired design. First International Conference on Design Creativity, Kobe, Japan, November 2010.

9. Altshuller; Creativity as an exact science, Gordon\& Breach, New York, USA, 1988.

10.Vincent, J. F.V., et al. Biomimetics: its practice and theory, Journal of the Royal Society Interface 3.9, 2006, 471-482

11.Vincent, JFV, and Mann DL. Systematic technology transfer from biology to engineering. Philosophical Transactions of the Royal Society of London A: Mathematical, Physical and Engineering Sciences 360.1791, 2002: 159-173.

12.Shevkoplyas S.S., Yoshida, T. \& Munn L.L. - Biomimetics Design of a Microfluidic Device for Auto.separation of Leukocytes from Whole Blood, American chemical society 2005.

13.Wanieck K., Pierre-Emmanuel Fayemi P., Maranzana N., C Zollfrank C., Shoshanah J. Biomimetics and its tools - Biomimetics and its tools - Vol. 6, n² 2, p.53-66 - 2017

14.Baumeister D, Tocke R, Dwyer J and Ritter S (2013) Biomimicry Resource Handbook: a Seed Bank of Best Practices. Biomimicry 3.8, Missoula, MT, USA.

15.Deldin, J.-M.; Schuknecht, M. The AskNature Database: Enabling Solutions in Biomimetic Design In: Goel AK, McAdams DA, Stone RB, eds. Biologically Inspired Design [Internet]. London: Springer London, 2014 [cited 2016 Mar 25]. p. 17-27.

16.Hooker, G., \& Smith, E. AskNature and the Biomimicry Taxonomy. Insight, 19(1), 4649 (2016)

17.Fayemi, P. E., Wanieck, K., Zollfrank, C., Maranzana, N., \& Aoussat, A. Biomimetics: process, tools and practice. Bioinspiration \& biomimetics, 12(1) (2017).

18.Jacobs SR, Nichol EC and Helms ME (2014) 'Where are we now and where are we going?' the BioM innovation database. Journal of Mechanical Design 136(11): 111101

19.Vandevenne, D., Verhaegen, P. A., Dewulf, S., \& Duflou, J. R. (2015). Product and organism aspects for scalable systematic biologically-inspired design. Procedia engineering, 131, 784-791.

20.Fayemi, P. E., Wanieck, K., Zollfrank, C., Maranzana, N., \& Aoussat, A. Biomimetics: process, tools and practice. Bioinspiration \& biomimetics, 12(1) (2017). 
21.Nagel, Robert L., et al. Exploring the use of functional models in biomimetic conceptual design, Journal of Mechanical Design 130.12 (2008): 121102.

22.Helms, M., Vattam, S. S., \& Goel, A. K. (2009). Biologically inspired design: process and products. Design Studies, 30(5), 606-622.

23. Bogatyreva O, Shillerov A, Bogatyrev N. Patterns in TRIZ contradiction matrix: integrated and distributed systems, In Proc. ETRIA World Conference TRIZ Future 2004, Florence, Italy, 5 November 2004. 